\title{
Analysis of Teaching Model of College Sports Clubs
}

\author{
Jun Huang \\ Physical Education Department, Southwest University of Science and Technology, Mianyang, \\ 621010, China
}

Keywords: sports clubs, teaching model, research and analysis

Abstract. Physical education course is one of required courses in colleges. A lot of researches and exploration have studied on teaching model of physical education, and there are many advanced teaching models. This paper mainly introduces teaching model of sports clubs, analyzes the significance, and puts forward problems and countermeasures etc.

\section{Introduction}

Physical education is one of required courses of colleges, and can enable students to establish awareness of lifelong physical exercise effectively and improve their physical quality. So, the teaching model of physical education has been a problem under exploration of colleges. Teaching model of sports clubs can combine students' sports hobbies with interests, give play to students' physical talent, improve effects and quality of college physical education, and thus become a common teaching model of physical education.

\section{Significance of taking teaching model of sports clubs for physical education}

At present, in college physical education, students accept and like teaching model of sports clubs, which has great actual significance.

(1) Help students establish awareness of lifelong physical exercise

College physical activities have a variety of forms, and the form of sports clubs can supplement and perfect the form of physical activities, and promote students to build awareness of lifelong physical exercise. Teaching model of sports clubs breaks limitation of traditional physical education, so that students will not be restricted by teaching hours, outline and plans etc, and could select form of physical education freely and choose content according to their hobbies, and cultivate their interest in physical education. As a result, this teaching model connects college physical education to social physical education, promotes students' physical exercise effectively, enhances students' physical quality, and benefits them lifelong.

(2) Help students establish healthy thoughts

College students are the future of the country, and thus it is of great significance to enhance physical quality and physique of college students. Thus, college physical education shall help students establish healthy thoughts. Teaching model of sports clubs is based on health, breaks methods and means of traditional teaching, focuses on healthy development of college students' body and mind, reduces proportion of sports, increases teaching content based on health, and ensures students' health, and enhances students' physique.

(3) Stimulate students' interest in participating in physical activities

Teaching model of sports clubs provides students with various types of sports items, cancels limitation of physical activities by classes, and breaks traditional physical education model. Such teaching model can meet different students' demands for physical exercise, and thus students could learn physical skills and knowledge in sports entertainment and competitions. While participating in physical activities, students with common physical interests and hobbies learn and exchange with each other and grow interactively, which break traditional monotonous physical education model, better mobilize students' enthusiasm for physical education, and enhance students' initiative in physical activities.

(4) Combine with extracurricular physical activities

In traditional physical education, physical courses and extracurricular physical activities are 
disjointed and cannot be effectively combined. Teaching model of sports clubs can combine college physical education with extracurricular sports interaction effectively and organically. With teaching model of sports clubs, students could choose their favorite sports items. In learning, physical education teachers instruct correctly, and regulate students' physical skills and knowledge, so that students could use these skills and knowledge in extracurricular physical activities, which ensures unity of college physical education and extracurricular physical activities.

(5) Promote cultural construction of colleges

Sports club develops on college campus recently, and is a new teaching model, and is supported and applied by colleges and becomes the focus of campus issues as it could meet actual needs of colleges. Teaching model of sports clubs mobilizes students' enthusiasm for participating in physical activities effectively, makes full use of sports venues and devices of colleges, and forms a positive vision. Under teaching model of sports clubs, students could select items in which they have interest independently. This links students with same interests, carries out a large number of physical activities, increases campus cohesion, and mobilizes students' enthusiasm and initiative for participating in physical education. Teaching model of sports clubs sublimates campus culture, enriches the connotation of campus culture, and promotes further development of campus culture.

\section{Problems in implementation of teaching model of sports clubs in colleges}

Chinese colleges have used teaching model of sports clubs for a short period of time, and have a great gap with foreign mature system. With China's education system reform, teaching model of college sports clubs obtains very good achievements and effects, but is still in the stage of primary application and has many problems to be solved.

(1) Problems in concepts

When utilizing teaching model of sports clubs, colleges lack teaching concepts with the core of students, and still take teachers as teaching subjects, lack concern about students' individualized development, and emphasize the leading role of teachers while ignoring students' role. Teaching model of sports clubs focuses on stimulating students' interest in physical exercise, promoting students' physical ability and thus strengthening effects of physical education. However, in actual teaching, colleges generally set up hot sports items and thus students have few sports items to choose from. Teachers control the progress of teaching completely, and students are in a passive position. Teachers generally focus on training students' physical knowledge and skills, and assign physical activity tasks for students subjectively, which inhibit students' enthusiasm for participating in physical activities and restrict students' individualized development.

(2) Disunity of physical education and extracurricular activities

Sports clubs of Chinese colleges generally have three forms. The first form is based on extracurricular activities and is to replace extracurricular physical activities with sports clubs. The second form is based on teaching and is to use sports clubs for physical education. The third form combines extracurricular physical activities with course teaching, and forms a unity in and out of classes. Currently, most colleges use the form based on teaching by sports clubs. However, in colleges, students have different physical foundation and physical qualities, and thus teaching model of sports clubs shall be changed according actual situation. Selection of teaching materials and teaching content of sports clubs lack hierarchy and pertinence, which cannot meet different levels of demands.

(3) Chaotic management of sports clubs

Management is important for carrying out sports clubs in colleges. However, actual management form is unitary and centralized, and is unable to meet development demand of sports clubs. Lots of college sports clubs have not clear objectives, and many students can only have classes in sports clubs during physical education, and fail to participate in interaction of sports clubs initiatively, and teachers have not effective methods and means to carry out physical education by using sports club teaching. In many colleges, sports clubs seem to have a huge organizational structure, but lack considerable plans and effective management, which greatly hinder the development of sports clubs. In addition, upon students' participation in physical activities of sports clubs, there is not 
corresponding check on work attendance and performance evaluation system, and there is a lack of flexible and effective management system. As a result, college sports clubs have chaotic management and thus affect effects and quality of physical education.

(4) Teacher building shall be strengthened

Nowadays, many college students have good economic conditions, and thus contact more with the society, have great foundation in terms of leisure, entertainment, fitness and sports, and have strong interest in and enthusiasm for some fashion sports. So, implementation of sports clubs in colleges shall not be limited in sports items, which proposes higher requirements for physical education teachers. In college sports clubs, teachers shall enhance students' physical quality by instructing them to have physical exercise, ensure their healthy growth and cultivate their habit of physical exercise. Then, work attitude, professional qualities, cultural accomplishment, speech and behaviors of teachers in sports clubs affect students' sports development directly. At present, in most college sports clubs, physical education teachers serve as part-time coaches of sports clubs, and have traditional teaching concepts and models, lack due qualities of modern coaches in sports clubs, and thus affect the actual role of college sports clubs.

(5) Lack of necessary funds

To establish sports clubs in colleges, a variety of sports items shall be set up in order to meet demands of different students. However, Chinese colleges increase enrollment constantly in recent years, which leads to huge increase of the number of college students and thus brings huge impacts on the development of college sports clubs. Sports clubs of many colleges have not enough venues and devices to meet demands of college physical education. Many college sports clubs are open to all students in the form of charging, and colleges input few funds in sports clubs, which seriously affect students' interest in participating in activities of sports clubs and reduces the quality of using sports clubs for physical education. In addition, the rise in prices of commodities drives rise in prices of devices of sports clubs, and economic input of sports clubs could not keep up the pace with the speed of rise in prices of commodities and colleges have not spare funds input, which make it difficult to carry out work of sports clubs, violate the role of sports clubs upon initial establishment, affect students' emotion and greatly hinder physical education.

\section{Solutions to problems in application of teaching model of sports clubs in colleges}

Teaching model of sports clubs in college physical education uses students' interest in physical education to enhance their physical education knowledge and skills, and thus trains students' habit of participating in physical exercise and establishing awareness of lifelong physical exercise. So, teaching model of sports clubs in college physical education is an advanced method and a development trend of the future. Chinese colleges shall promote such a teaching model, accumulate experience to perfect teaching methods constantly, and improve the quality of college physical education.

(1) Change learning concept and be student-oriented

When applying teaching model of sports clubs for physical education, colleges shall be fully student-oriented, provide students with physical activities and needs that they have interest in, and deepen students' understanding of physical education knowledge and skills. Students could choose sports items freely in sports clubs according to their interests and hobbies, and then select physical education teachers freely with the proceeding of physical education. For physical education, physical activities shall be set up according to students' interests, students and teachers shall cooperate with each other and complete learning jointly. The form of sports clubs used in physical education shall be targeted, epochal and time-based, and be humanized, scientific, simple and reasonable to operate during implementation, and be student-centered, and focus on enhancing students' physical education knowledge and skills, training students' awareness of lifelong physical exercise and strengthening students' physique.

(2) Unify teaching content in and out of physical education

Setting of sports items of sports clubs shall refer to extracurricular physical activities, so that these clubs could help physical education and combine with extracurricular physical activities. 
Sports clubs could achieve teaching objectives of physical education, lay a foundation for students to participate in extracurricular physical activities, combine physical education with extracurricular activities organically and promote students' rapid growth.

(3) Perfect management system of sports clubs

Operation of sports clubs requires a sound and standard management system with clear responsibilities of sports club managers. Organization and management structure shall be established correspondingly according to different purposes of sports clubs, and select responsible persons to manage sports clubs strictly according to sound management rules and regulations, formulate work plans and summary and perfect work attendance checking system, so that sports clubs could really give play to the due role, and achieve rapid and standard development.

(4) Strengthen teacher building

Colleges shall introduce professionals constantly to promote the development of sports clubs, provide training for physical education teachers, and enhance teachers' overall qualities. Colleges shall firstly create an external environment to enhance teachers' professional skills, increase research capacity of physical education, and enhance teaching effects. Finally, colleges shall train young teachers constantly, make them grow rapidly, and instruct students in sports clubs.

(5) Expand funds channels

Construction of sports clubs in colleges needs a large amount of funds, and channels of funds source shall be expanded constantly. Colleges could contact enterprises for funds sponsorship. This not only obtains funds, but also provides opportunities for enterprise promotion, benefits mutually both colleges and enterprises, enhances the overall level of sports clubs, and increases the popularity of enterprises among students.

\section{Conclusions}

Teaching model of college sports clubs is an advanced teaching method with epochal character, and can combine with students' interests to teach physical education. This could make students better master physical education skills and knowledge, train students' habit of participating in physical exercise effectively, and establish awareness of correct lifelong physical exercise. Although the teaching model of current sports clubs is not sound, there will be such a teaching model that is suitable for actual situation of Chinese colleges through research of all physical education teachers and relevant scholars, in order to enhance the quality of college physical education and cultivate more excellent talents.

\section{References}

[1] Sun Yuhang. Superiority of Physical Education Model of College Sports Clubs [J]. Journal of Jilin Business and Technology College. 2010 (05).

[2] He Jiandong, Luo Bingquan. Research on Physical Education Mode in Universities Sports Clubs in China [J]. Sports Culture Guide. 2010 (10).

[3] Chen Xinlin. On Teaching Model of Sports Club of Our College [J]. Sports World Scholarly. 2009 (07).

[4] He Xueyun. Study on Teaching Model of College Sports Clubs [J]. Heilongjiang Science and Technology Information. 2009 (24).

[5] Liang Jianxiu. Exploring the Teaching System of Sport Club in Independent Colleges [J]. Journal of Guangzhou Physical Education Institute. 2010 (04). 